\title{
Global Lung Function Standardisation: Finally Making Our Dream a Reality?
}

\author{
Gaetano Caramori ${ }^{\mathrm{a}}$ Paolo Paredi $^{\mathrm{b}}$ \\ ${ }^{a}$ Centro Interdipartimentale per lo Studio delle Malattie Infiammatorie delle Vie Aeree e Patologie Fumo-correlate

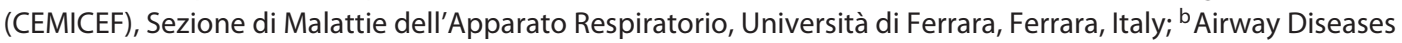 \\ Section, National Heart and Lung Institute, Imperial College London, London, UK
}

In this issue of Respiration, Brazzale et al. [1] investigate the clinical implications of changing from the commonly used current spirometry equations for references values, such as the European Community for Steel and Coal (ECSC) [2], the National Health and Nutrition Examination Survey (NHANES III) [3] and the Stanojevic all-ages reference equations [4] to the Global Lung Function Initiative (GLI2012) equations.

The GLI2012 (http://www.lungfunction.org) equations are the result of a huge international cooperation and have already been endorsed by six international scientific societies (the American College of Chest Physicians, the American Thoracic Society, the Asian Pacific Society of Respirology, the Australian and New Zealand Society of Respiratory Science, the European Respiratory Society and the Thoracic Society of Australia and New Zealand) and incorporated into the software equipment of many spirometers. Data from 74,187 healthy nonsmoker (57.1\% females) subjects, aged 3-95 years, from 72 centres in 33 countries, were studied to derive multiethnic reference equations and age-dependent lower limits of normal (LLN) [5].

The authors of this Herculean effort should be congratulated by the scientific community for providing us with these long-awaited reference values. Lung function tests provide us with vital information in our everyday clinical practice. However, spirometric indices vary with

\section{KARGER}

E-Mail karger@karger.com

www.karger.com/res age, sex, height and ethnic group. Until now, it has been difficult to interpret spirometry, particularly in geriatric patients and in different ethnic groups. Crucially, the main advantage of the GLI2012 equations is that they are applicable over a wider age range (3-95 years of age) than any other published reference data and, in addition, robust predicted values for multiple ethnic groups are available.

As we are consulted by increasingly ageing populations [6], in the absence of clear LLN, it is often frustrating to correctly attribute clinical relevance to subtle respiratory symptoms and borderline ventilatory abnormalities in elderly patients who may present with many concomitant co-morbidities that could provide an alternative (and often more plausible) explanation for their symptoms. In addition, spirometry may also be influenced by ethnicity [7] and, as we are practising clinicians in an increasingly cosmopolitan world, this variable is now very relevant.

The authors report a change in the prevalence rates of airflow obstruction of up to $32 \%$ between the three equations (NHANES III, the Stanojevic equations and GLI2012). Notably, these discrepancies were due to differences in LLN rather than in mean values for $\mathrm{FEV}_{1} / \mathrm{FVC}$ ratios. Switching to the GLI2012 spirometry reference values will impact on the interpretation of spirometry test results, and the magnitude and direction of the change depends upon which reference data are used. 
The results presented in the study by Brazzale et al. [1] on the diagnostic consequences of adopting the new GLI2012 reference values are very similar to those obtained previously, using a larger cohort of 17,572 subjects (49.5\% females) aged 18-85 years from hospitals in Australia and Poland [5]. In both studies [1, 8], the presence of airflow obstruction was defined as an $\mathrm{FEV}_{1} / \mathrm{FVC}$ ratio $<$ LLN. In addition, in the Australian/Polish study [8], the presence of Global Initiative for Obstructive Lung Disease (GOLD) grades 2-4 [9] was also defined as the presence of an $\mathrm{FEV}_{1} / \mathrm{FVC}<70 \%$ and $\mathrm{FEV}_{1}<80 \%$ predicted.

Again, in both studies $[1,8]$, the predicted $\mathrm{FEV}_{1}, \mathrm{FVC}$, $\mathrm{FEV}_{1} / \mathrm{FVC}$ and LLN were calculated using the new GLI2012 and the old ECSC [2] and NHANES III [3] equations. In the study by Brazzale et al. [1], these values were also calculated and compared using the Stanojevic equations [4], which, however, utilise data predominantly from the NHANES III dataset in the adult age-range [1]. Remarkably, the prevalence of airflow obstruction is pretty similar using all the reference equations ([1]: see table 4). However, in agreement with previous studies [10], using the criteria of the GOLD grades 2-4, there is an apparent over-diagnosis of chronic obstructive pulmonary disease (COPD) in older subjects compared to when using the new GLI2012 criteria [8]. The hot topic of the best diagnostic criteria for COPD is clinically relevant, highly debated $[11,12]$ and needs to be adequately addressed with further investigations. In fact, as with controlled clinical trials of drugs, the 'patient-oriented evidence that matters' approach applied to the study of the lung function dictates that many well-designed, carefully-conducted, prospective cohort studies must be performed before this new evidence becomes a grade- $A$ diagnostic recommendation (http://www.cebm.net/?O=1025).

Considering the elevated prevalence of COPD in many countries [13], it is becoming particularly urgent to perform long-term prospective cohort studies in order to better understand the true clinical relevance of the different phenotypes of COPD [9], related and unrelated to chronic tobacco-smoking [14] and defined using the LNN calculated with the new GLI2012 equations. As recognised by the authors of the GLI2012, more information is also required about pulmonary function in other ethnic groups and additional data from the Indian subcontinent as well as from Arab, Polynesian and Latin American countries and Africa will further improve these equations in the future. In addition, more studies are required to elucidate the influence of country of birth on the level of lung function [5]. In conclusion, in order to perform these studies as soon as possible, we need worldwide large investments at all levels in both the public and private sectors with the aim of finally making our dream a reality.

\section{References}

-1 Brazzale DJ, Hall GL, Pretto JJ: Effects of adopting the new Global Lung Function Initiative 2012 reference equations on the interpretation of spirometry. Respiration 2013;86: 183-189.

-2 Quanjer PH, Tammeling GJ, Cotes JE, Pedersen OF, Peslin R, Yernault JC: Official Statement of the European Respiratory Society: Lung volumes and forced ventilatory flows. Report Working Party Standardization of Lung Function Tests, European Community for Steel and Coal. Eur Respir J 1993;16(sup$\mathrm{pl}): 5-40$.

$>3$ Hankinson JL, Odencrantz JR, Fedan KB: Spirometric reference values from a sample of the general U.S. population. Am J Respir Crit Care Med 1999;159:179-187.

4 Stanojevic S, Wade A, Stocks J, Hankinson J, Coates AL, Pan H, Rosenthal M, Corey M, Lebecque P, Cole TJ: Reference ranges for spirometry across all ages: a new approach. Am J Respir Crit Care Med 2008;177:253-260.

$\checkmark 5$ Quanjer PH, Stanojevic S, Cole TJ, Baur X, Hall GL, Culver BH, Enright PL, Hankinson JL, Ip MS, Zheng J, et al, ERS Global Lung
Function Initiative: Multi-ethnic reference values for spirometry for the 3-95 years age range: the global lung function 2012 equations. Eur Respir J 2012;40:1324-1343.

6 Christensen K, Doblhammer G, Rau R, Vaupel JW: Ageing populations: the challenges ahead. Lancet 2009;374:1196-1208.

7 Braun L, Wolfgang M, Dickersin K: Defining race/ethnicity and explaining difference in research studies on lung function. Eur Respir J 2013;41:1362-1370.

8 Quanjer PH, Brazzale DJ, Boros PW, Pretto JJ: Implications of adopting the Global Lungs 2012 all-age reference equations for spirometry. Eur Respir J 2013, E-pub ahead of print.

9 Vestbo J, Hurd SS, Agustí AG, Jones PW, Vogelmeier C, Anzueto A, Barnes PJ, Fabbri LM, Martinez FJ, Nishimura M, et al: Global strategy for the diagnosis, management and prevention of chronic obstructive pulmonary disease, GOLD executive summary. Am J Respir Crit Care Med 2013;187:347-365.

10 Vollmer WM, Gíslason T, Burney P, Enright PL, Gulsvik A, Kocabas A, Buist AS: Comparison of spirometry criteria for the diagnosis of
COPD: results from the BOLD study. Eur Respir J 2009;34:588-597.

11 Quanjer P, Fragoso CA, Miller MR, Güder G, Störk S, Hoes AW, Rutten F: GOLD or lower limit of normal definition? A letter and authors' response. Respir Res 2012;13:61-62(author reply 62-63).

12 Quanjer PH, Stanojevic S, Swanney MP, Miller MR: Recommendations for epidemiological studies on COPD. Eur Respir J 2012;39: 1277-1278;(author reply 1278-1279).

13 Buist AS, McBurnie MA, Vollmer WM, Gillespie S, Burney P, Mannino DM, Menezes AM, Sullivan SD, Lee TA, Weiss KB, et al, BOLD Collaborative Research Group: International variation in the prevalence of COPD (the BOLD study): a population-based prevalence study. Lancet 2007;370:741-750 (erratum published in Lancet 2012;380:806).

14 Hooper R, Burney P, Vollmer WM, McBurnie MA, Gislason T, Tan WC, Jithoo A, Kocabas A, Welte T, Buist AS: Risk factors for COPD spirometrically defined from the lower limit of normal in the BOLD project. Eur Respir J 2012;39:1343-1353. 